\title{
Variabilidades fenotípica e genotípica de estirpes de Staphylococcus aureus isoladas em casos de mastite subclínica bovina
}

\author{
Phenotypic and genotypic variabilities of Staphylococcus aureus strains isolated from bovine \\ subclinical mastitis
}

\author{
Luciano Menezes Ferreira ${ }^{1}$ Antonio Nader Filho ${ }^{2}$ Erika de Oliveira ${ }^{3}$ \\ Luiz Francisco Zafalon ${ }^{4}$ Viviane de Souza ${ }^{5}$
}

\section{RESUMO}

Foram submetidas a PCR-Ribotipagem e aos testes de sensibilidade in vitro frente a 12 antimicrobianos 77 estirpes de Staphylococcus aureus isoladas em amostras de leite procedentes de 40 vacas da raça holandesa que apresentaram mastite subclínica, em uma propriedade rural localizada no Estado de São Paulo, Brasil. Os resultados obtidos revelaram quatro diferentes padrões de resistência a antimicrobianos, sendo observada a predominância de resistência à lincomicina entre 19 (24,7\%) estirpes de S.aureus. As 58 (75,3\%) estirpes restantes foram sensíveis aos 12 antimicrobianos testados. A PCR-ribotipagem revelou a ocorrência de nove padrões genotípicos distintos, além de apresentar uma capacidade discriminatória maior $(D=0,82)$ que a obtida nos antibiogramas $(D=0,42)$. Entre as 19 estirpes resistentes aos antimicrobianos, 14 (73,7\%) foram agrupadas em três padrões de ribotipagem e, destas, 13 (92,9\%) apresentaram resistência à eritromicina e à lincomicina, isoladamente ou em associação. o grande número de ribotipos e de padrões de resistência a antimicrobianos observados nesta propriedade demonstrou que há grande heterogeneidade genética em populações naturais de $\mathbf{S}$. aureus, fato este que deve ser levado em consideração em programas de controle da mastite bovina.

Palavras-chave: mastite, Staphylococcus aureus, variabilidade fenotípica e genotípica.

\section{ABSTRACT}

Seventy-seven S. aureus strains, isolated in milk samples obtained from 40 Holstein cows suffering from subclinical mastitis in a dairy herd in the state of São Paulo -
Brazil, were undergone to PCR-ribotyping and in vitro susceptibility testing to 12 antimicrobial drugs. PCR-ribotyping revealed nine different patterns and presented a higher discriminatory power $(D=0.82)$ in comparison with the in vitro antibiotic susceptibility test $(D=0.42)$. Moreover, the results showed four antibiotic resistance patterns, with the resistance to lincomycin being the most predominant and comprising 19 (24.7\%) S. aureus strains. The other 58 (75.3\%) isolates were sensitive to all antibiotics tested. Of the 19 isolates which presented resistance to antibiotics, 14 (73.7\%) were grouped in three ribotypes, and 13 (92.9\%) of them were resistant to eritromycin and/or lincomycin. The large number of ribotypes and antibiotic resistance patterns found in this single dairy herd showed that one must be careful when considering the results of in vitro susceptibility tests obtained from a few $S$. aureus strains, because there is a high heterogeneity among naturally occurring populations of $S$. aureus, which must be taken into consideration in control programs against bovine mastitis.

Key words: mastitis, Staphylococcus aureus, phenotypic and genotypic variabilities.

\section{INTRODUÇÃO}

O Staphylococcus aureus é reconhecido como sendo o patógeno mais freqüentemente isolado em casos de mastite subclínica, relacionado entre os microrganismos mais contagiosos. Por isso, há grande importância com cuidados que previnam a sua

${ }^{1}$ Programa de Doutorado em Medicina Veterinária Preventiva, Departamento de Medicina Veterinária Preventiva e Reprodução Animal, Faculdade de Ciências Agrárias e Veterinárias (FCAV), Universidade Estadual Paulista (UNESP). Via de acesso Prof. Paulo Donato Castellane, s/n., Rural, 14884-900, Jaboticabal, SP, Brasil. E-mail: ferreira_lm@yahoo.com.br. Autor para correspondência. ${ }^{2}$ Departamento de Medicina Veterinária Preventiva e Reprodução Animal, FCAV, UNESP, Jaboticabal, SP, Brasil.

${ }^{3}$ Programa de Doutorado do Departamento de Microbiologia, FCAV, UNESP, Jaboticabal, SP, Brasil.

${ }^{4}$ Instituto de Zootecnia, Centro de Análise e Pesquisa Tecnológica dos Agronegócios - Bovinos de Leite, Nova Odessa, SP, Brasil. ${ }^{5}$ Programa de Mestrado em Medicina Veterinária Preventiva, Departamento de Medicina Veterinária Preventiva e Reprodução Animal, FCAV, UNESP, Jaboticabal, SP, Brasil. 
disseminação no rebanho, durante a ordenha. Os quartos mamários infectados, a pele do úbere e dos tetos são os principais sítios de localização desses agentes. Da mesma forma, os bocais da ordenhadeira e as mãos dos ordenhadores são considerados como as principais vias de transmissão (GRINDAL, 1988; MYLLYS et al., 1997).

O $\boldsymbol{S}$. aureus pode ser isolado em outros locais, tanto em vacas e novilhas quanto no alimento, na sala de ordenha e até mesmo em portadores humanos, ressaltando a importância do manejo, durante a ordenha, na prevenção de sua transmissão. Além disso, animais portadores podem constituir fonte de infecção permanente, permitindo a persistência do $\boldsymbol{S}$. aureus durante toda a fase de lactação (BRAMLEY \& DODD, 1984; ROBERSON et al., 1998).

Existe heterogeneidade genética considerável em populações naturais de $\boldsymbol{S}$. aureus (TENOVER et al., 1994; KAPUR et al., 1995), a qual pode ser explorada para investigar a disseminação de estirpes de $\boldsymbol{S}$. aureus de origens humana e animal. A avaliação desses traços heterogêneos inclui as variações das características bioquímicas e de sensibilidade a antimicrobianos, a fagotipagem, o perfil da presença de plasmídeos, o estudo das regiões variáveis dos genes da coagulase, da região $\mathrm{X}$ da proteína A e do espaçador intergênico entre as regiões 16S e 23S do RNA ribossomal, a amplificação aleatória de segmentos genômicos (RAPD-PCR) e a macrorrestrição do DNA celular total detectada pela eletroforese de campo pulsado (LANGE et al., 1999). No entanto, embora haja diferentes métodos para a tipagem de isolados de $\boldsymbol{S}$. aureus, nem todos apresentam eficiência equivalente no que diz respeito a suas capacidades discriminatórias.

A técnica que vem sendo amplamente utilizada em estudos epidemiológicos é a da PCRribotipagem. Esse método foi desenvolvido com a finalidade de permitir a amplificação de regiões polimórficas do espaçador intergênico da região 16S23S do RNA ribossomal, o que possibilita a tipificação de isolados de $\boldsymbol{S}$. aureus de importância epidemiológica de forma simples e rápida (KOSTMAN et al., 1995; FORSMAN et al., 1997). Esses espaçadores intergênicos estão localizados entre os genes do RNA ribossomal e podem diferir em tamanho e em número de cópias, em decorrência da semelhança ou da diversidade existentes entre as estirpes analisadas (CUNY et al., 1996).

Partindo-se do princípio de que um determinado rebanho e propriedade possam ter diversidade fenotípica e genotípica das estirpes envolvidas nos casos de mastite subclínica por $\boldsymbol{S}$. aureus, pode-se esperar que ocorra uma correlação dessas diferenças com o controle da mastite. Assim sendo, idealizou-se o presente trabalho com o objetivo de conhecer as variabilidades fenotípica e genotípica das estirpes de Staphylococcus aureus isoladas dos casos de mastite subclínica bovina de um rebanho específico em uma única propriedade rural.

\section{MATERIAL E MÉTODOS}

Foram isoladas 77 estirpes de Staphylococcus aureus em amostras de leite procedentes de 40 vacas aparentemente sadias, porém reagentes ao California Mastitis Test (SCHALM \& NOORLANDER, 1957), em uma propriedade rural produtora de leite tipo $\mathrm{C}$ situada no município de Colina; SP, no período de 2001-2002. O rebanho leiteiro era constituído por vacas mestiças 7/8 holandesa, variedade preta e branca, ordenhadas mecanicamente uma vez ao dia, utilizando-se o sistema de "balde ao pé”, cuja produção global média situava-se em torno de 400 litros diários.

Após a semeadura do leite em placas de ágar, sangue a $5 \%$ e incubação a $37^{\circ} \mathrm{C}$, durante 18 a 24 horas, foram submetidas à verificação morfológica em esfregaços corados pelo método de Gram todas as colônias hemolíticas que apresentassem coloração branco-acinzentada ou amarelo-ouro. Aquelas que se revelassem com cocos Gram-positivos, dispostos ou não sob a forma de cachos de uva, foram submetidas às provas da catalase e da coagulase lenta em plasma de coelho (HOLMBERG, 1973). As estirpes catalase e coagulase positivas foram submetidas, ainda, às provas para verificação da produção de acetoína (Caldo MRVP - Oxoid ${ }^{\circledR}$, Hampshire, Inglaterra), para a diferenciação entre Staphylococcus aureus, Staphylococcus hyicus, Staphylococcus delphini e Staphylococcus intermedius. As amostras que produziram acetoína foram testadas quanto à utilização ou não da maltose e da trealose (Vetec ${ }^{\circledR}$, Rio de Janeiro, Rio de Janeiro, Brasil), para a diferenciação entre Staphylococcus aureus e Staphylococcus schleiferi subespécie coagulans. As estirpes que mostraram-se positivas a estas provas foram classificadas como sendo de Staphylococcus aureus (HOLT et al., 1994).

A extração de DNA das estirpes de $\boldsymbol{S}$. aureus foi efetuada de acordo com a técnica de HOOKEY et al. (1998) e, por meio da amplificação de fragmento de DNA cromossomal específico para a espécie $\boldsymbol{S}$. aureus, seguindo o protocolo descrito por MARTINEAU et al. (1998), foi feita a identificação molecular das estirpes isoladas. 
Após a identificação molecular das estirpes de $\boldsymbol{S}$. aureus isoladas, foram realizados os testes de sensibilidade in vitro a partir da técnica de difusão em disco (BAUER et al., 1966), em placas de ágar MüellerHinton, de acordo com o recomendado pelo Comitê Nacional para Padrões em Laboratório Clínico - NCCLS (padrão aprovado M7-A5, 2000), frente a 12 antimicrobianos representados pela ampicilina $(10 \mu \mathrm{g})$, cefalotina $(30 \mu \mathrm{g})$, eritromicina $(15 \mu \mathrm{g})$, gentamicina $(30 \mu \mathrm{g})$, lincomicina (2(g), neomicina $(30 \mu \mathrm{g})$, norfloxacina $(10 \mu \mathrm{g})$, oxacilina $(1 \mu \mathrm{g})$, penicilina (10UI), sulfazotrim $(25 \mu \mathrm{g})$, tetraciclina $(30 \mu \mathrm{g})$ e vancomicina

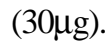

Para a discriminação entre as estirpes de $\boldsymbol{S}$. aureus, foi realizada, de acordo com o protocolo descrito por CUNY et al. (1996), a técnica de PCRribotipagem, com modificações referentes às concentrações dos reagentes utilizados para as reações. As reações de amplificação consistiram em 20mM Tris-HCl, (pH 8,4), 50mM KCl, 1,5 $\mathrm{mM} \mathrm{MgCl}_{2}$, $200 \mu \mathrm{M}$ de cada desoxinucleotídeo, $10 \mu \mathrm{M}$ de cada primer (Life Technologies, Rockville, USA) rRNA1 (5'TTG TACACACCG CCC GTCA-3') erRNA2 (5'-GGT ACC TTA GAT GTT TCA GTT C-3’) e 1U de Taq polimerase (Gibco BRL, Rockville, USA), em volume final de $20 \mu \mathrm{L}$. As condições de amplificação compreenderam desnaturação inicial a $94^{\circ} \mathrm{C}$ por 5 minutos, seguida de 30 ciclos de $94^{\circ} \mathrm{C}$ por 1 minuto, $55^{\circ} \mathrm{C}$ por 1 minuto e $72^{\circ} \mathrm{C}$ por 1 minuto, com extensão final a $72^{\circ} \mathrm{C}$ por 4 minutos. Os produtos amplificados foram observados em gel de agarose em concentração de 1,5\%, corado com brometo de etídio; e, como padrão de peso molecular, foi utilizado o Ladder 100bp.

A avaliação da capacidade discriminatória foi determinada de acordo com o índice numérico descrito por HUNTER \& GASTON (1988). O valor (D) indica a probabilidade de duas estirpes isoladas de forma aleatória em uma população-teste serem relacionadas em grupos distintos no método de tipagem avaliado.

\section{RESULTADOS E DISCUSSÃO}

A tabela 1 mostra que, entre as 77 estirpes de $\boldsymbol{S}$. aureus submetidas aos testes de sensibilidade in vitro frente aos 12 antimicrobianos, 58 (75,3\%) revelaram-se sensíveis a todos os princípios ativos testados. As 19 estirpes restantes foram agrupadas em 4 padrões de resistência distintos, sendo o padrão de resistência LIN (lincomicina) predominante quando considerado de forma isolada $(9,1 \%)$ ou em conjunto (6,5\%). Segundo estudos de LANGE et. al. (1999), na região Sul do Brasil, 48,5\% dos isolados de $\boldsymbol{S}$. aureus de casos de mastite bovina foram suscetíveis a todos os antimicrobianos testados, inclusive à lincomicina, sendo observado que $43,9 \%$ dos isolados foram resistentes à penicilina $G$ e à ampicilina, de forma particular ou em associação. No presente estudo, esse padrão foi obtido em apenas 2,6\% das amostras.

Na tabela 2 e na figura 1, pode-se observar a distribuição das estirpes de $\boldsymbol{S}$. aureus com seus respectivos padrões de resistência, destacando-se os períodos I, J e K, com 48 (62,3\%) estirpes de $\boldsymbol{S}$. aureus isoladas, dentre as quais $14(73,7 \%)$ apresentaram padrões de resistência aos antimicrobianos. Além disso, entre as 5 (26,3\%) estirpes restantes, que também apresentaram padrões de resistência aos antimicrobianos, 4 (21,0\%) foram isoladas nos períodos E e F e 1 (5,3\%) no período B.

Nas tabelas de 2 a 4 e na figura 1 , verifica-se maior freqüência de isolamento de $\boldsymbol{S}$. aureus nos períodos I, J e K. Esse aumento talvez possa ser atribuído aos elevados índices pluviométricos verificados entre dezembro de 2001 e fevereiro de 2002, cuja média mensal foi de 317,3mm. Assim sendo, essa média foi muito superior à observada no período de dezembro de 2000 a fevereiro de 2001, cuja média mensal foi de $140,9 \mathrm{~mm}$, conforme os índices fornecidos pelo Pólo Regional de Desenvolvimento Tecnológico dos Agronegócios da Alta Mogiana, Colina, SP. Acreditase que esse fato, além de dificultar a manutenção das condições higiênicas a serem adotadas durante a ordenha, propiciaria condições de umidade e de temperatura mais favoráveis à sobrevivência e/ou proliferação dos referidos microrganismos. Observase ainda que nesse período foram isoladas estirpes com novos padrões genotípicos (7, 8 e 9), sugerindo a ocorrência de mutação ou de maior dispersão no

Tabela 1 - Padrões de resistência aos antimicrobianos das estirpes de $\boldsymbol{S}$. aureus isoladas em casos de mastite subclínica bovina, Colina/SP, abril/2001 a abril/2002.

\begin{tabular}{llll}
\hline \multirow{2}{*}{ Padrão } & $\begin{array}{c}\text { Fenótipo de resistência aos } \\
\text { antimicrobianos * }\end{array}$ & \multicolumn{2}{c}{ Estirpes isoladas } \\
\cline { 3 - 4 } & Eri & 5 & $\mathrm{~N}^{\circ}$ \\
\hline 1 & Lin & 7 & 6,5 \\
2 & Amp/Pen & 2 & 9,1 \\
3 & Eri/Lin & 5 & 6,6 \\
4 & $-* *$ & 58 & 75,3 \\
5 & & 77 & 100,0 \\
Total & & & \\
\hline
\end{tabular}

*Ampicilina (Amp), Eritromicina (Eri), Lincomicina (Lin), Penicilina (Pen).

**Sensíveis a todos antimicrobianos testados 
Tabela 2 - Distribuição das estirpes de $\boldsymbol{S}$. aureus com respectivos padrões de resistência aos antimicrobianos de acordo com o período de obtenção, Colina/SP, abril/2001 a abril/2002.

\begin{tabular}{|c|c|c|c|c|c|c|c|c|c|c|c|c|c|}
\hline \multirow[b]{2}{*}{ Padrão } & \multicolumn{11}{|c|}{ Período de obtenção * } & \multicolumn{2}{|c|}{ Amostras/ padrão } \\
\hline & A & $\mathrm{B}$ & $\mathrm{C}$ & $\mathrm{D}$ & $\mathrm{E}$ & $\mathrm{F}$ & $\mathrm{G}$ & $\mathrm{H}$ & I & $\mathrm{J}$ & K & $\mathrm{N}^{\circ}$ & $\%$ \\
\hline 1 & & & & & & & & & 2 & & 3 & 5 & 6,5 \\
\hline 2 & & 1 & & & 2 & 1 & & & 3 & & & 7 & 9,1 \\
\hline 3 & & & & & & & & & 2 & & & 2 & 2,6 \\
\hline 4 & & & & & & 1 & & & & 2 & 2 & 5 & 6,5 \\
\hline 5 & 1 & 2 & 5 & 1 & 4 & 2 & 6 & 3 & 8 & 12 & 14 & 58 & 75,3 \\
\hline Total & 1 & 3 & 5 & 1 & 6 & 4 & 6 & 3 & 15 & 14 & 19 & 77 & 100,0 \\
\hline
\end{tabular}

${ }^{*} \mathrm{~A}=26 / 04 / 01 ; \mathrm{B}=17 / 05 / 01 ; \mathrm{C}=08 / 06 / 01 ; \mathrm{D}=04 / 07 / 01 ; \mathrm{E}=30 / 08 / 01 ; \mathrm{F}=20 / 09 / 01 ; \mathrm{G}=25 / 10 / 01 ; \mathrm{H}=29 / 11 / 01 ; \mathrm{I}=14 / 03 / 02 ; \mathrm{J}=04 / 04 / 02 ;$ $\mathrm{K}=25 / 04 / 02$.

ambiente das estirpes oriundas de diferentes fontes de contaminação, de modo a propiciar introdução de novas estirpes de $\boldsymbol{S}$. aureus no rebanho.

A tabela 3 mostra que as 15 (19,5\%) estirpes de $\boldsymbol{S}$. aureus caracterizadas como pertencentes ao padrão 2 de amplificação da região intergênica 16S-23S do RNA ribossomal, ou seja, ribotipo 2, foram as que apresentaram uma distribuição mais homogênea durante todo o período de obtenção das amostras. No entanto, as estirpes pertencentes ao ribotipo 3 foram as que evidenciaram maior prevalência $(29,9 \%)$ no rebanho, seguidas pelas pertencentes ao ribotipos 5 e 1 , as quais foram isoladas em 20,7 e 13,0\% dos casos, respectivamente. Observa-se, também, na tabela 3 , que a maioria (48) das estirpes de $\boldsymbol{S}$. aureus foi isolada das amostras de leite colhidas durante os períodos I (15), J (14) e K (19). Verifica-se ainda que nesses períodos não foram isoladas estirpes pertencentes ao ribotipo 6 , sendo constatado um único caso de estirpes pertencentes ao ribotipo 2 .

$\mathrm{Na}$ tabela 2, observa-se que, entre 19 estirpes de $\boldsymbol{S}$. aureus resistentes aos princípios ativos testados, ocorre a concentração em apenas três padrões genotípicos (2, 3 e 5), com 14 (73,7\%) estirpes. Dentre essas, 13 (92,7\%) estirpes evidenciaram resistência frente aos antimicrobianos eritromicina e lincomicina, isoladamente ou em associação. Observase também que todas as estirpes do padrão 2 da PCRribotipagem apresentaram o mesmo padrão de resistência à LIN, enquanto que o ribotipo 5 da PCRribotipagem apresentou uma grande diversidade, com a presença de todos os padrões de resistência aos antimicrobianos obtidos.

Tendo em vista o fato de todas as estirpes terem sido isoladas em amostras de leite oriundas de vacas pertencentes a uma única propriedade e

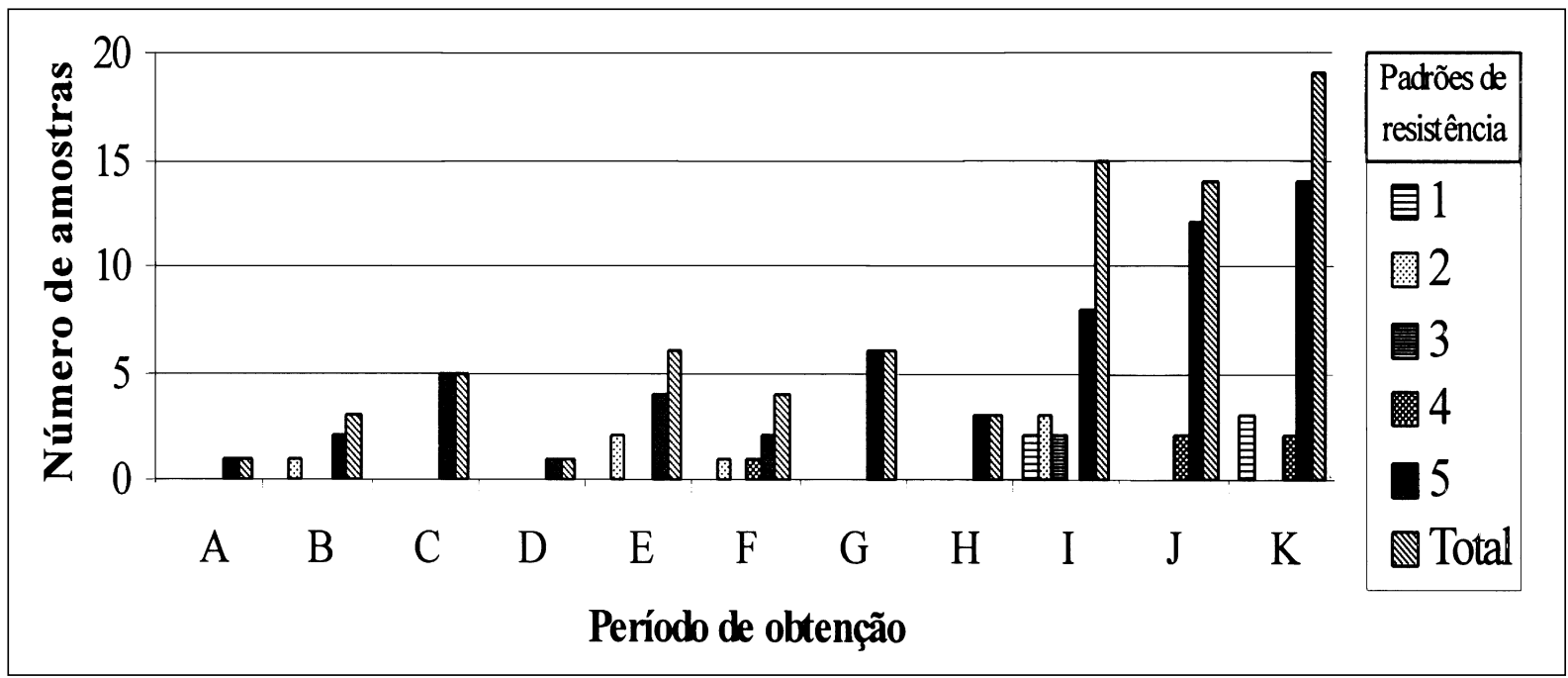

Figura - 1 - Distribuição das estirpes de $\boldsymbol{S}$. aureus com respectivos padrões de resistência aos antimicrobianos de acordo com o período de obtenção, Colina/SP, abril/2001 a abril/2002. 
Tabela 3 - Distribuição das estirpes de $\boldsymbol{S}$. aureus de acordo com o período de obtenção, com os respectivos padrões de amplificação da região intergênica 16S-23S do RNA ribossomal relacionados aos padrões de resistência aos antimicrobianos, Colina, SP, abril/2001 a abril/2002.

\begin{tabular}{|c|c|c|c|c|c|c|c|c|c|c|c|c|c|}
\hline \multirow[b]{2}{*}{ Padrão } & \multicolumn{11}{|c|}{ Período de obtenção * } & \multicolumn{2}{|c|}{ Amostras/padrão } \\
\hline & A & B & $\mathrm{C}$ & $\mathrm{D}$ & $\mathrm{E}$ & $\mathrm{F}$ & G & $\mathrm{H}$ & I & $\mathrm{J}$ & K & $\mathrm{N}^{\circ}$ & $\%$ \\
\hline 1 & & & & & & & & & $1(2)$ & & & 10 & 13,0 \\
\hline 2 & & $1(2)^{* *}$ & & & $2(2,2)$ & $1(2)$ & & & $1(2)$ & & & 15 & 19,5 \\
\hline 3 & & & & & & & & & & & $4(1,1,1,4)$ & 23 & 29,9 \\
\hline 4 & & & & & & & & & & & 1(4) & 5 & 6,5 \\
\hline 5 & & & & & & $1(4)$ & & & $2(1,2)$ & $1(4)$ & 1(3) & 16 & 20,7 \\
\hline 6 & & & & & & & & & & & & 1 & 1,3 \\
\hline 7 & & & & & & & & & $1(3)$ & & & 3 & 3,9 \\
\hline 8 & & & & & & & & & & $1(1)$ & & 1 & 1,3 \\
\hline 9 & & & & & & & & & & & $1(1)$ & 3 & 3,9 \\
\hline Total & - & 1 & - & - & 2 & 2 & - & - & 5 & 2 & 7 & 77 & 100,0 \\
\hline
\end{tabular}

${ }^{*} \mathrm{~A}=26 / 04 / 01 ; \quad \mathrm{B}=17 / 05 / 01 ; \quad \mathrm{C}=08 / 06 / 01 ; \quad \mathrm{D}=04 / 07 / 01 ; \quad \mathrm{E}=30 / 08 / 01 ; \quad \mathrm{F}=20 / 09 / 01 ; \quad \mathrm{G}=25 / 10 / 01 ; \quad H=29 / 11 / 01 ; \quad \mathrm{I}=14 / 03 / 02 ; \quad J=04 / 04 / 02 ;$ $\mathrm{K}=25 / 04 / 02$.

$* *($ ) = padrões de resistência aos antimicrobianos

considerando que nenhum animal de outro rebanho foi introduzido na linha de ordenha, os dados inseridos na figura 1 e nas tabelas 2 e 3 chamam a atenção pela elevada variedade dos padrões fenotípicos e genotípicos, ou seja, 5 e 9 padrões distintos, respectivamente. Este fato pode ser atribuído à considerável heterogeneidade genética existente entre populações naturais de $\boldsymbol{S}$. aureus (TENOVER et al., 1994; KAPUR et al., 1995). A elevada variabilidade dos padrões fenotípicos e genotípicos pode decorrer ainda da diversidade dos locais nos quais os $\boldsymbol{S}$. aureus são encontrados, uma vez que estes microrganismos podem ser isolados no leite de vacas infectadas, na superfície da pele dos tetos de vacas e de novilhas, em restos de alimentos, em bocais de ordenhadeira mecânica e até mesmo nas mãos e fossas nasais de portadores humanos (BRAMLEY \& DODD, 1984; ROBERSON et al. 1994; 1998).

A PCR-ribotipagem, em relação ao teste de sensibilidade aos antimicrobianos, apresentou melhor poder discriminatório, com valor $D$ igual a 0,82 . Nessa técnica, foram identificados 9 padrões de amplificação

Tabela 4 - Distribuição das estirpes de $\boldsymbol{S}$. aureus e dos respectivos padrões de amplificação da região intergênica 16S-23S do RNA ribossomal de acordo com o período de obtenção, Colina, SP, abril/2001 a abril/2002.

\begin{tabular}{|c|c|c|c|c|c|c|c|c|c|c|c|c|c|}
\hline \multirow[b]{2}{*}{ Padrão } & \multicolumn{11}{|c|}{ Período de obtenção * } & \multicolumn{2}{|c|}{ Amostras/ padrão } \\
\hline & A & $\mathrm{B}$ & $\mathrm{C}$ & $\mathrm{D}$ & $\mathrm{E}$ & $\mathrm{F}$ & G & $\mathrm{H}$ & I & $\mathrm{J}$ & K & $\mathrm{N}^{\circ}$ & $\%$ \\
\hline 1 & & & 1 & & & & 1 & & 5 & 3 & & 1 & 5,3 \\
\hline 2 & 1 & 3 & 1 & & 5 & 3 & & 1 & 1 & & & 5 & 26,2 \\
\hline 3 & & & 2 & 1 & & & 1 & 1 & 1 & 5 & 12 & 4 & 21,1 \\
\hline 4 & & & 1 & & & & & & & 1 & 3 & 1 & 5,3 \\
\hline 5 & & & & & & 1 & 4 & 1 & 5 & 3 & 2 & 5 & 26,2 \\
\hline 6 & & & & & 1 & & & & & & & - & - \\
\hline 7 & & & & & & & & & 2 & 1 & & 1 & 5,3 \\
\hline 8 & & & & & & & & & & 1 & & 1 & 5,3 \\
\hline 9 & & & & & & & & & 1 & & 2 & 1 & 5,3 \\
\hline Total & 1 & 3 & 5 & 1 & 6 & 4 & 6 & 3 & 15 & 14 & 19 & 19 & 100,0 \\
\hline
\end{tabular}

*A=26/04/01; B=17/05/01; C=08/06/01; D=04/07/01; E=30/08/01; F=20/09/01; G=25/10/01; H=29/11/01; I=14/03/02; J=04/04/02; $\mathrm{K}=25 / 04 / 02$. 
distintos, com número e tamanho dos fragmentos variados. Assim, na tabela 3, pode-se observar a distribuição das estirpes de $\boldsymbol{S}$. aureus, com seus respectivos padrões de amplificação da região intergênica 16S-23S do RNA ribossomal, durante o período de obtenção.

Como era de se esperar, a PCR-ribotipagem revelou melhor poder discriminatório $(D=0,82)$ que o teste de sensibilidade aos antimicrobianos $(\mathrm{D}=0,42)$. Este achado significa que, em estudos epidemiológicos, a técnica da PCR-ribotipagem mostrou-se mais adequada que os testes de sensibilidade aos antimicrobianos. Tais achados foram semelhantes aos obtidos por AARESTRUP et al. (1995); LANGE et al. (1999), que encontravam valores da ordem de $(0,86)$ e $(0,85)$, respectivamente.

Segundo TENOVER et al. (1994), a combinação de dois ou mais métodos de tipagem proporciona maior possibilidade de discriminação dos padrões das estirpes estudadas. Neste sentido, observa-se, na tabela 4, onde o padrão 5 da ribotipagem apresenta resistência a todos os antimicrobianos testados, a importância do uso de pelo menos duas técnicas para discriminar, ainda mais, as estirpes em estudo.

A análise dos dados constantes da tabela 2 e na figura 1 mostra que, caso fosse feito um antibiograma entre as estirpes isoladas nos primeiros cinco meses (A a E) de colheita, seria obtido somente um padrão de resistência aos antimicrobianos (LIN). Assim, se esse resultado fosse extrapolado para o tratamento de todos os outros animais, a chance de insucesso seria muito elevada, uma vez que surgiram outros padrões de resistência entre os períodos F e K.

Os diferentes ribotipos (9 padrões) de $\boldsymbol{S}$. aureus encontrados no leite dos animais desse rebanho fechado indicam que a PCR-ribotipagem pode ser utilizada como ferramenta importante na detecção de fontes de contaminação e de vias de transmissão das diferentes estirpes do agente na propriedade, para direcionar medidas preventivas e corrigir, se necessário, as que estão sendo aplicadas.

Assim sendo, depreende-se que os resultados obtidos no presente trabalho contribuem para o esclarecimento de pelo menos um fator determinante do insucesso de um programa de tratamento, qual seja, a ineficácia do medicamento utilizado, mesmo que a sua escolha tenha se fundamentado nas informações oferecidas pelos testes de sensibilidade in vitro.

\section{CONCLUSÕES}

As variações nos padrões fenotípicos e genotípicos encontradas no presente estudo mostram que, em um determinado rebanho e período, pode existir considerável heterogeneidade genética em populações naturais de $\boldsymbol{S}$. aureus, de modo a dificultar o controle e o tratamento da mastite subclínica bovina. Tais achados chamam a atenção para o risco de falhas no tratamento desta enfermidade, caso sejam extrapoladas para todos os animais do rebanho as informações oferecidas pelos testes de sensibilidade a antimicrobianos obtidas a partir de algumas poucas estirpes de S. aureus.

\section{REFERÊNCIAS}

AARESTRUP, F. et al. Prevalence of coagulase gene polymorphism in Staphylococcus aureus isolates causing bovine mastitis. Can J Vet Res, Ottawa, v.59, p.124-128, 1995.

BAUER, A.W. et al. Antibiotic susceptibility testing by a standardized single disc method. Am J Clin Pathol, Hagerstown, v.45, p.493-496, 1966.

BRAMLEY, A.J.; DODD, F.H. Reviews of the progress of dairy science: mastitis control - progress and prospects. J Dairy Res, Cambridge, v.51, p.481-512, 1984.

CUNY, C. et al. Discrimination of S. aureus by PCR for r-RNA gene spacer size polymorphism and comparison to SmaI macrorestriction patterns. Zentralbl Bakteriol, Stuttgart, v.283, p.466-476, 1996.

FORSMAN, P. et al. Identification of staphylococcal and streptococcal causes of bovine mastitis using 16S-23S rRNA spacer regions. Microbiology, v.143, p.3491-3500, 1997.

GRINDAL, R.J. The role of the milking machine in mastitis. Br Vet J, v.144, p.524-533, 1988.

HOLMBERG, O. Staphylococcus epidermidis isolated from bovine milk. Acta Vet Scand, v.45, p.1-144, 1973.

HOLT, J. G. et al. Gram-positive cocci. In: HOLT, J.G.; KRIEG, N.R.; SNEATH, P.H.A.; STALEY, J. T., WILLIAN, S,T. Bergey's manual of determinative bacteriology. 9.ed. Baltimore: Williams e Wilkins, 1994. p.544-551.

HOOKEY, J.V. et al. Molecular typing of Staphylococcus aureus based in PCR restriction fragment length polymorphism and DNA sequence analysis of the coagulase gene. J Clin Microbiol, Washington, v.36, n.4, p.1083-1089, 1998.

HUNTER, P.R.; GASTON, M.A. Numerical index of discriminatory ability of typing systems: an application of Simpson's index of diversity. J Clin Microbiol, Washington, v.26, p.2465-2466, 1988.

KAPUR, V. et al. Molecular population genetic analisis of Staphylococcus aureus recovered from cows. J Clin Microbiol Washington, v.33, p.376-380, 1995. 
KOSTMAN, J. et al. A universal approach to bacterial molecular epidemiology by polymerase chain reaction ribotyping. J Infect Dis, Chicago, v.171, p.204-208, 1995.

LANGE, C. et al. Molecular subtyping of Staphylococcus aureus isolates from cases of bovine mastitis in Brazil. Vet Microbiol, Amsterdam, v.67, p.127-141, 1999.

MARTINEAU, F. et al. Species-specific and ubiquitous-DNAbased assays for rapid identification of Staphylococcus aureus. J Epidem, v.17, p.595-604, 1998.

MYLLYS, V. et al. Persistence in bovine mastitis of Staphylococcus aureus clones as assessed by random amplified polymorphic DNA analysis, ribotyping and biotyping. Vet Microbiol, v.51, p.245-251, 1997.

National Committee for Clinical Laboratory Standards (NCCLS). Methods for dilution antimicrobial susceptibility tests for bacteria that grow aerobically. Approved Standards M7-A5. Wayne, PA, Approved Standards: $5^{\text {th }}$ ed.Pennsylvania: NCCLS, 2000. 36p.

ROBERSON, J.R. et al. Ecology of Staphylococcus aureus isolated from various sites on dairy farms. J Dairy Sci Savoy, v.77, p.3354-3364, 1994.

ROBERSON, J.R. et al. Sources of intramammary infections from Staphylococcus aureus in dairy heifers at first parturition. J Dairy Sci, v.81, n.3, p.687-693, 1998.

SCHALM, O.W.; NOORLANDER, D.D. Experiments and observations leading to development of the California Mastitis Test. J Am Vet Res, v.130, n.5, p.199-204, 1957.

TENOVER, F.C. et al. Comparison of traditional and molecular methods of typing isolates of Staphylococcus aureus. J Microbiol, Washington, v.32, p.407, 1994. 